Employment Effects of Skill Biased Technological

Change when Benefits are Linked to Per-Capita Income

Matthias Weiss

43-2004

January 2004 


\title{
Employment Effects of Skill Biased Technological Change when Benefits are Linked to Per-Capita Income
}

\author{
Matthias Weiss* \\ mea, Universität Mannheim \\ 68131 Mannheim, Germany \\ weiss@mea.uni-mannheim.de
}

\begin{abstract}
This paper studies the employment effects of technological change when benefits are endogenous. If the (i) level of welfare aid depends on the general income level in the economy and (ii) wages for unskilled workers cannot fall below the level of welfare aid, there is a link between the wage for unskilled labor and the productivity of skilled labor. An increase in the latter will lead to an increase in average income and hence the level of welfare aid. This in turn leads unions to ask for higher wages for unskilled workers.

Technological change is shown to have employment effects (only) if it is skill-biased and if this link exists.

Keywords: Unemployment, Skill-Biased Technical Change, Union Wage Setting

JEL Classification: E24, J31, J50, O30
\end{abstract}

${ }^{*}$ I am indebted to Martin Hellwig for ongoing discussion and advice. I would also like to thank Philippe Aghion, Melanie Lührmann, and Lia Pacelli for valuable comments and suggestions. The usual disclaimer applies. Financial support by the Deutsche Forschungsgemeinschaft is gratefully acknowledged. 


\section{Introduction}

This paper argues that skill-biased technological change has adverse employment effects because the unskilled workers' wages are linked to the skilled workers' productivity. This link is established by the indexation of benefits to per-capita income.

If the unemployed receive payments from the state (unemployment benefits, welfare aid, etc.), workers are not willing to work for wages below these payments. If these payments to unemployed - which constitute workers' fall-back income - are linked to indices of standards of living (as measured, eg, by per-capita income), an increase in (only) the skilled workers' productivity leads to an increase in the level of benefits - via an increase in per-capita income. This increase in benefits makes unions ask for higher wages for the unskilled. An increase in skilled workers' productivity can thereby lead to an increase in unskilled workers' wages.

In this paper, I examine an economy in which the level of benefits depends on percapita income. The idea is that benefits are paid to avoid poverty so that their level must be closely related to the "subsistence level". But poverty is a relative concept and so is the subsistence level. ${ }^{1}$ In developed industrial countries, the subsistence level is certainly more than just the amount of money that suffices to guarantee survival. In societies where most of the people can afford video cameras, mobile phones, flights to distant countries, etc., a life without electric light, running water or even without a television set $^{2}$ is considered inacceptable. The "subsistence level" is considered as the level that guarantees a "decent life". The latter, in turn, depends on the average standard of living in the respective society. Thus, the "subsistence level" is an endogenous quantity depending on the general standard of living. This implies that the level of benefits should depend on the general income level. ${ }^{3}$

Figure 1 gives some empirical support to this claim. For further empirical evidence, see Appendix A.1. The correlation between the rate of welfare benefits for a four-person

\footnotetext{
${ }^{1}$ See eg Foster (1998): "Absolute versus Relative Poverty" and the other contributions to the session on "What is Poverty and Who are the Poor?" in the AEA Papers and Proceedings Issue of the American Economic Review of May 1998.

${ }^{2}$ The German right of distraint legislation considers a television set as indispensable and excludes it from seizure.

${ }^{3}$ In fact, most benefit systems have unemployment insurance elements that depend on the level of past earnings rather than the general income level of the economy. But for two reasons, I think that these unemployment benefits are not the proper measure for the fall-back income of workers:

1. Unemployment benefits are generally limited in duration. After a certain time limit, eligibility for unemployment benefits expires and unemployed workers receive welfare aid. So, in the long run, it is welfare aid that constitutes the fall-back income.

2. For unskilled workers, unemployment benefits may easily fall short of the level of welfare aid. In this case, the payment is increased to the level of welfare aid. So, the level of welfare aid rather than the level of unemployment benefits constitutes the lower bound to low-skill wages.
} 
Benefits Vs GDP per Capita in 1990 Prices, West Germany 1970 - 1998

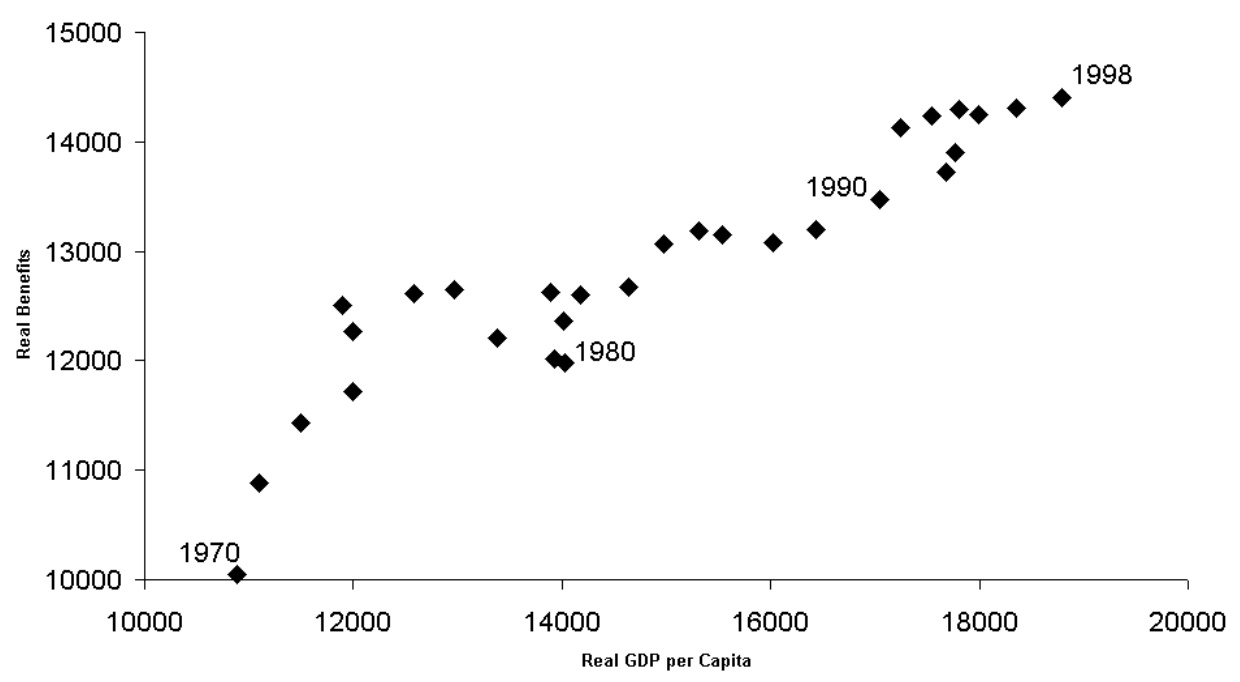

Figure 1: Vertical axis: Benefits: German Welfare Rate ("Sozialhilfe-Eckregelsatz") for a fourperson household (two adults, two children) in Euros in consumer prices of 1990, Source: German Federal Ministry of Labor. Horizontal axis: GDP per Capita in Germany: in Euros in consumer prices of 1990, Source: EuroStat.

household and per-capita GDP in Germany between 1970 and 1998 has been 0.93.

Endogeneity of the level of benefits is important because it introduces a feedback mechanism: Because benefits constitute a fall-back income for workers, the level of benefits affects the level of wages. Since wages make up an important part of total income, fluctuations in wages result in changes in average income. This in turn affects the level of benefits and the wheel turns full circle: There is a feedback from wages to benefits and back to wages.

This paper studies this feedback mechanism and its effects on the wage structure and on employment in the presence of skill-biased technical change. ${ }^{4}$

I consider an economy with two kinds of productive labor, high wage-earning skilled labor and low wage-earning unskilled labor. Following papers on related issues (see, eg, Davis (1998) and Krugman (1995)), I assume that the market for skilled labor clears, while the market for unskilled labor does not. ${ }^{5}$

This classification into a competitive market for skilled labor and a non-competitive market for unskilled labor is somewhat in contrast to the literature on "Dual Labor Mar-

\footnotetext{
${ }^{4}$ It is shown below, that employment effects of technical change arise only if this link from average income to benefits exists and if technical change is "skill biased".

${ }^{5}$ In Davis (1998), the wage for unskilled labor is modelled as an exogenously given fixed minimum wage while in Krugman (1995), it is assumed to be a fixed proportion of the skilled workers' wage.
} 
kets" ${ }^{6}$ and on "Efficiency Wages" where it is typically assumed that the market for unskilled labor is competitive and clears whereas the market for skilled labor is regulated and fails to clear. This latter view is, however, at variance with the evidence on unemployment and wage flexibility in Europe. It is the unskilled workers who are by far more likely to be unemployed which is evident from Table 1 .

Regarding the effects of wage bargaining on wage flexibility, Büttner and Fitzenberger (1998, p. 1) find that in Germany,

“... employees with low wages have significantly lower wage flexibility than high wage employees. This effect is particularly relevant for the lower educational groups."

Therefore, I assume that the wage for unskilled labor is determined by a monopolistic labor union while employment is determined by competitive firms. ${ }^{7}$ The assumption that the wage for skilled labor be entirely flexible is for simplicity. The focus of this paper is on the (strikingly large) extent to which the unskilled workers' rate of unemployment exceeds that of the skilled workers. The fact that unemployment also exists among the skilled workers might indeed be explaind by considerations of insider-outsider relations or efficiency wages so that these theories might be seen as complementary rather than contradictory to this paper.

Table 1: West German Unemployment Rates by Education, Men, Average: 1983 - 1994

\begin{tabular}{ccc}
\hline Low Education $^{\mathrm{a}}$ & Medium Education $^{\mathrm{b}}$ & High Education $^{\mathrm{c}}$ \\
\hline $8.42 \%$ & $3.37 \%$ & $1.79 \%$ \\
\hline
\end{tabular}

Source: GSOEP 1984-1995. a) low or medium secondary schooling degree (Hauptschule or Realschule, b) high secondary schooling degree (Abitur) or any form of formal postsecondary education other than university or technical college - for instance vocational training, c) any degree from a technical college (Fachhochschule) or university.

As a result of union wage-setting, the wage for unskilled labor depends on the unskilled workers' reservation wage as measured, eg, by the level of benefits. As was argued above, the benefits are in turn a function of the income levels of both unskilled and skilled workers. This interdependence between wages and benefits yields an allocation where

\footnotetext{
${ }^{6}$ See, eg, Saint-Paul (1997).

${ }^{7}$ In Section 5, this assumption is relaxed in two ways. Subsection 5.5 shows that similar results are obtained in a modified version of the model where the market for unskilled labor is assumed to be competitive. In subsection 5.1, the general Nash-Bargaining solution is used to model the wage determination. Both modifications do not affect the results substantially.
} 
the wage for unskilled labor depends positively on the wage for skilled labor (even if the marginal productivities of the two factors are independent of each other) while the latter adjusts to clear the market for skilled labor. The obtained wage rigidity is a rigidity in the relation between the wages for unskilled and skilled labor. In other words, the wage for unskilled labor is too rigid with respect to the unskilled workers' productivity and it is overly sensitive to changes in the skilled workers' wages.

In particular, it is shown that if - through skill-biased technological change - the productivity of the skilled workers rises faster than that of the unskilled workers, the wage of the latter increases by more than would be justified by their productivity gains (because it is linked to the skilled workers' wage via the benefits). As a result, employment of unskilled labor falls. The matter of concern here is not that the (unskilled workers') wage falls too little - as in standard union models - but that it rises too much. This result is unique to this model where the feedback mechanism from wages to benefits and back to wages is accounted for.

Autor and Duggan (2003) study a similar transmission mechanism in a related context. They argue that increasing wage inequality in conjunction with an indexation of disability benefits to the mean wage has led to a rising replacement ratio of disability benefits in the U.S. They estimate that this phenomenon (together with reduced screening stringency) has driven down the U.S. unemployment rate by two thirds of a percentage point because unskilled workers "became almost twice as likely to exit the labor force in the event of an adverse shock - and correspondingly less likely to enter unemployment." (p. 198)

In the context of identification and specification of aggregate wage equations, Manning (1993) and Blanchard and Katz (1999) also consider endogenous benefits. Manning (1993) argues that the lack of identification can be overcome even in the case of endogenous benefits if the replacement ratio can be assumed to be exogenous. Blanchard and Katz (1999) reconcile the seemingly contradictory evidence and theory on the relation between wages and unemployment by recognizing that unemployment benefits depend on past earnings. Both papers consider homogenous labor so that the asymmetries with regard to skills as discussed in this paper are not an issue.

The findings in this paper are consistent with the evolution of wages and employment of unskilled workers in Europe over the past decades. Wages for all skill levels have risen steadily over this period and, by and large, the employment prospects of the less skilled workers have deteriorated. ${ }^{8}$

There has been increasing consensus among labor market economists that asymmetric technical progress and possibly increasing trade with low wage-countries have led to a substantial shift in demand away from unskilled workers toward skilled workers during the 1980's and the 1990's. ${ }^{9}$ In the United States (and the UK), it seems, this demand shift

\footnotetext{
${ }^{8}$ See, eg, Siebert (1997).

${ }^{9}$ Levy and Murnane (1992) and Gottschalk and Smeeding (1997) give surveys of the empirical literature on this subject.
} 
has led to an increase in wage inequality while in (continental) Europe, where the wage structure has remained fairly stable, it resulted in a rise in unemployment, in particular among unskilled workers. ${ }^{10}$ This coincidence of rising wage inequality in the United States and rising unemployment (at rather stable relative wages) in Europe suggests that the kind of feedback mechanism described in this paper has been an important feature of labor markets in Europe while in the United States it has not. This is consistent with the observation that welfare systems are in general more generous and unions are stronger in Europe than they are in the U.S.

The results in the paper do not rely on any complementarity or substitution relations between the different types of labor in production. All that matters is that the wage determination at the unskilled level is tied to the wage for skilled labor via the benefits. In fact, similar results are obtained if the workers' utilities depend not just on their income but considerations of envy and the like introduce a preference for relative wealth. ${ }^{11}$

The remainder of the paper is organized as follows. The basic model is set up in Section 2. Section 3 examines the interdependence of wages and benefits. Comparative statics are analyzed in Section 4. Section 5 assesses the robustness of the results and Section 6 summarizes and concludes.

\section{The Model}

Consider an economy with a continuum of measure 1 of homogeneous firms producing a single good. The good is produced using two input factors, unskilled and skilled labor.

\section{Technology}

The firm produces according to the production function

$$
Y=\left(a_{u} \cdot l_{u}\right)^{\rho}+\left(a_{s} \cdot l_{s}\right)^{\rho}, \quad 0<\rho<1, \quad 0<a_{u}<a_{s}
$$

where $Y$ is the quantity of the final good, $l_{u}$ and $l_{s}$ are the levels of employment of unskilled and skilled labor respectively, and $\rho, a_{u}$, and $a_{s}$ are productivity parameters. This specification has the following properties:

- The elasticity of substitution between unskilled and skilled labor is $\sigma=1 /(1-\rho)>$ 1. I restrict the analysis to substitution elasticities larger than one because only in

\footnotetext{
${ }^{10}$ See, eg, Freeman (1995), Krugman (1994), Siebert (1997), and Davis (1998). For a critique to this view, see, eg, Nickell and Bell (1996).

${ }^{11}$ See, eg, Veblen (1999, p. 31): "The end sought by accumulation is to rank high in comparison with the rest of the community in point of pecuniary strength."

The role of social status is also stressed in Weiss and Fershtman (1998, p. 810): “... 'guest workers' and immigrants are less reluctant to accept low status work, partially because they do not compare themselves with local workers. In addition, it is considered less 'unfair' to pay them low wages, given the low wage in their country of origin."
} 
this case does skill-biased technological change have adverse effects on the relative position of the unskilled workers. ${ }^{12}$

- The marginal productivities of unskilled and skilled workers are independent of each other and the cross wage elasticities of the factor demands are zero. This has the advantage that any relation between the wages for the two kinds of labor that arises in the model can be attributed solely to the institutional peculiarities.

These restrictions are also for simplicity. In Section 5.2, I consider the case of a more general CES technology. The results are shown to be independent of these different specifications.

\section{Demands for Unskilled and Skilled Labor}

The firm sells its product on the world market at the world market price $P=1$ (by choice of the numéraire). At given wage levels, the firm chooses the level of employment so as to maximize its profit

$$
\pi=Y-w_{u} \cdot l_{u}-w_{s} \cdot l_{s}
$$

The demand for unskilled and skilled labor is respectively

$$
l_{u}^{d}\left(w_{u}\right)=\left(\frac{\rho \cdot a_{u}^{\rho}}{w_{u}}\right)^{\frac{1}{1-\rho}} \quad \text { and } \quad l_{s}^{d}\left(w_{s}\right)=\left(\frac{\rho \cdot a_{s}^{\rho}}{w_{s}}\right)^{\frac{1}{1-\rho}},
$$

where $w_{u}$ and $w_{s}$ are the wages for unskilled and skilled labor respectively.

\section{Workers}

All workers share the same utility function

$$
u(\text { net wage })=\ln (\text { net wage }) \text {. }
$$

Both types of labor are each supplied by a continuum of measure 1 of homogeneous workers. Each worker inelastically supplies one unit of labor.

\section{Benefits}

As will be seen below, the model involves unemployment of unskilled workers. All unemployed are assumed to receive benefits, $\tilde{w}$. In accordance with the reasoning in the introduction, the benefits are assumed to depend on the net average income

$$
\tilde{w}=\mu \cdot(1-t) \cdot \frac{Y}{2}, \quad 0<\mu<1,
$$

where $Y / 2$ is per-capita income and $t$ is the income tax rate.

\footnotetext{
${ }^{12}$ Furthermore, the majority of the empirical estimates are between 1 and 2. See, eg, Autor, Katz, and Krueger (1999) who argue that a consensus estimate is a value around 1.5.
} 


\section{Government}

The benefits are financed through a proportional income tax. The tax rate $t$ is endogenously determined by the government's budget constraint:

$$
\left(1-l_{u}\right) \cdot \tilde{w}=t \cdot Y
$$

\section{The Union's Objective Function}

All unskilled workers are assumed to be members of the labor union. The union is assumed to maximize the expected utility of its representative member conditional on the wage level.

$$
U=E\left[u(\text { net wage }) \mid w_{u}\right]=l_{u}\left(w_{u}\right) \cdot \ln \left[(1-t) \cdot w_{u}\right]+\left[1-l_{u}\left(w_{u}\right)\right] \cdot \ln \tilde{w}
$$

The first term in expression (7) represents the probability for any union member to become (or remain) employed (conditional on the wage level) times the utility derived from (net) labor income. The second term represents the conditional probability to become unemployed times the utility derived from the alternative income (ie, benefits).

\section{Wage Determination}

As was argued above, the wage for unskilled labor is assumed to be determined by a monopolistic labor union whereas the level of employment is determined by the firm.

The union maximizes its objective function taking into account the effect of the wage level on employment. I assume that, out of idleness or lack of comprehension of the economic system, the union does not account for the second-round effects the wage has on the level of benefits and on the tax rate. ${ }^{13}$ In the formal model, this means that the objective function (7) is maximized subject to (3) but taking the level of benefits $\tilde{w}$ and the tax rate $t$ as exogenously given.

Solving the maximization problem yields the following result which is familiar from the literature:

Lemma 1 Under the above assumptions, the wage for unskilled labor, $w_{u}$, is an increasing function of the level of benefits, $\tilde{w}$ :

$$
w_{u}=e^{1-\rho} \cdot \frac{\tilde{w}}{1-t} .
$$

\section{The Interdependence of Wages and Benefits}

In contrast to standard union models (and in contrast to what the union takes into account), in this model, the level of benefits is a function of the net average income which,

\footnotetext{
${ }^{13}$ This assumption is also for simplicity. In Section 5.1, I consider the case where the union takes into full account the effects of the wage level on the level of benefits and the tax rate. The results are virtually unaffected.
} 
in turn, is a function of - among others - the wage for unskilled labor. Accounting for this endogeneity in (8) yields ${ }^{14}$

$$
w_{u}^{*}=\frac{1}{2} \cdot e^{1-\rho} \cdot \mu \cdot\left[\left(\frac{\rho \cdot a_{u}}{w_{u}^{*}}\right)^{\frac{\rho}{1-\rho}}+a_{s}^{\rho}\right] .
$$

The equilibrium wage for unskilled labor, $w_{u}^{*}$, is implicitly given by this equation. ${ }^{15}$

It is easily verified that under the above assumptions, an equilibrium, $w_{u}^{*}\left(a_{u}, a_{s}, \mu, \rho,.\right)$, exists and is unique. ${ }^{16}$

\section{Comparative Statics}

The comparative static properties of the equilibrium allocation are presented in the following propositions:

Proposition 1 An increase [respectively decrease] in the unskilled workers' productivity, as measured by the productivity parameter $a_{u}$, leads to an increase [respectively decrease] in both, the equilibrium wage for unskilled labor and the level of employment.

$$
\begin{gathered}
\frac{\partial w_{u}^{*}}{\partial a_{u}} \cdot \frac{a_{u}}{w_{u}^{*}}=\frac{\eta_{Y, l_{u}}}{1-\rho+\eta_{Y, l_{u}}}>0 \\
\frac{\partial l_{u}^{*}}{\partial a_{u}} \cdot \frac{a_{u}}{l_{u}^{*}}=\frac{\rho-\eta_{Y, l_{u}}}{1-\rho+\eta_{Y, l_{u}}}>0
\end{gathered}
$$

where $\eta_{Y, l_{i}}=\frac{\partial Y}{\partial l_{u}} \cdot \frac{l_{u}}{Y}$.

A decrease in the unskilled workers' productivity leads - via a decrease in the average income - to a decrease in the unskilled workers' wage. But this decrease is less than would be required by the productivity loss because the wage is linked to the average income level which decreases by less than the unskilled workers productivity. Therefore employment falls. This failure of the wage to fully adjust to changes in productivity can be seen as a rigidity in the relative wage $w_{u} / w_{s}$.

While the wage for skilled labor always adjusts to clear the market, the wage for unskilled labor depends on the productivities of both, unskilled and skilled workers. In

\footnotetext{
${ }^{14}$ Equations (8) and (9) are just two different ways of writing down the same result. In equation (8) the focus is on the dependency of the unskilled workers' wage on the level of (endogenous) benefits while in equation (9) the unskilled workers' wage is shown as a function of the exogenous parameters of the model.

${ }^{15}$ Throughout the paper, the term "equilibrium" will be used to refer to the allocation which results from union wage setting, given the other institutional features of the model.

${ }^{16}$ Existence: For $w_{u}$ sufficiently small (resp. sufficiently large), the right hand side of the equilibrium condition (9) is larger (resp. smaller) than the left hand side. As both sides of the equation are continuous in $w_{u}$ there must exist at least one value of $w_{u}, w_{u}^{*}$, for which both sides are equal. Uniqueness: The left hand side of (9) is strictly increasing in $w_{u}$ whereas the right hand side is strictly decreasing in $w_{u}$. Therefore, if a solution to (9), $w_{u}^{*}$, exists, it must be unique.
} 
other words, the wage for unskilled labor is linked to the wage for skilled labor. The relative wage cannot fully adjust to changes in the relative productivity. This rigidity leads to an increase in unemployment in response to a decrease in the productivity for the unskilled workers.

Similar results are obtained in standard union models where the reservation wage of the workers is exogeneous.

Proposition 2 An increase [respectively decrease] in the skilled workers' productivity, as measured by the productivity parameter $a_{s}$, leads to an increase [respectively decrease] in the wage for unskilled labor and a decrease [respectively increase] in the level of employment.

$$
\begin{aligned}
& \frac{\partial w_{u}^{*}}{\partial a_{s}} \cdot \frac{a_{s}}{w_{u}}=\frac{(1-\rho) \cdot \eta_{Y, l_{s}}}{1-\rho+\eta_{Y, l_{u}}}>0 \\
& \frac{\partial l_{u}^{*}}{\partial a_{s}} \cdot \frac{a_{s}}{l_{u}^{*}}=-\frac{\eta_{Y, l_{s}}}{1-\rho+\eta_{Y, l_{u}}}<0
\end{aligned}
$$

The increased productivity of the skilled workers leads to a rise in the average income. This in turn increases - through higher benefits - the unskilled workers' reservation wage and thereby their wage. Since the productivity of the unskilled remains unchanged, the demand for unskilled labor and thereby employment falls.

While the result in Proposition 1-that the wage falls too little in response to a fall in the productivity of the unskilled - is also obtained in standard union models, the result in Proposition 2 - that the wage increases too much in response to a productivity gain of the skilled workers - is unique to this model where the feedback mechanism from income levels to wages is accounted for. In this model, the driving force behind both effects is the above mentioned rigidity in the relative wage.

Propositions 1 and 2 consider cases where only one type of labor becomes more productive. Depending on whose producitivity increases, unemployment increases or decreases. Since in reality, technological change tends to affect the productivities of different types of labor at the same time, the question arises which of the two opposite effects dominates. The following Proposition answers this question.

Proposition 3 Technological change leads to an decrease [respectively increase] in employment whenever it leads to an increase [respectively decrease] in $\frac{a_{s}}{a_{u}}$.

$$
\frac{\partial l_{u}^{*}}{\partial \frac{a_{s}}{a_{u}}} \cdot \frac{a}{l_{u}^{*}}=-\frac{\eta_{Y, l_{s}}}{1-\rho+\eta_{Y, l_{u}}}<0
$$

Skill-biased technical progress favoring the skilled workers' productivity in a way that leads to an increase in $a_{s} / a_{u}$ has a negative effect on the relative demand for unskilled labor, $l_{u}^{d} / l_{s}^{d}$. Since the relative wage for unskilled labor, $w_{u} / w_{s}$, cannot fully adjust to 
this shift in labor demand, employment of unskilled workers falls. On the other hand, if the productivity of unskilled workers grows faster [or falls more slowly] than the skilled workers' productivity, the wage for unskilled labor increases [respectively falls], but by less [respectively more] than would be justified by the shift in the relative productivity so that the employment of unskilled workers increases. Any technical change that leaves the ratio $a_{s} / a_{u}$ unaffected has no effect on the level on employment.

This result is consistent with the common view that it is the same factors that boost wage inequality in the U.S. and the UK and result in higher unemployment in (continental) Europe. ${ }^{17}$ In a model in which the welfare system is less generous and wages are to a greater extent market-determined - the alleged features of US labor markets - skillbiased technical change (in the form of an increase in $a_{s} / a_{u}$ ) leads to an increase in wage inequality. Appendix A.1 provides some empirical underpinning for this result.

Increasing trade with low wage countries has been cited as a second culprit of the rise in wage inequality in the United States. ${ }^{18}$ In fact, in a two-sector version of this model, it can be shown that increasing trade with low wage countries (as modeled by a decrease in the relative price of the import good - whose production is assumed to be intensive in the use of unskilled labor) has exactly the same effect on wages and employment as does skillbiased technical change (as modeled by an increase in $a_{s} / a_{u}$ ). Increasing trade with low wage countries also leads to a (downward) shift in the relative demand for unskilled labor. As the relative wage for unskilled labor does not fully adjust, employment of unskilled labor falls.

Proposition 3 has important policy implications. Any increase in the relative productivity (or more general in the relative "market value") of the skilled workers leads to a higher rate of unemployment in this model. This argument is valid even if the absolute productivity of the unskilled workers increases as well (but less than proportionately). Education policy must therefore aim at improving the skills of the unskilled workers relative to those of the skilled.

\section{Robustness Considerations}

In this section, some critical assumptions of the model are relaxed or modified. The robustness of the above stated results with respect to these modifications is assessed.

\subsection{Generalized Nash-Bargaining}

In Sections 2 through 4 the wage for unskilled labor is assumed to be set unilaterally by the union. In this section I consider the more general case of wage negotiations between the

\footnotetext{
17 "The rise in joblessness in Europe is thus the flip side of the rise in earnings inequality in the U.S.", Freeman (1995, p. 19)

${ }^{18}$ See, eg, Wood (1994) and more recently Wood (1998).
} 
union and firms. The outcome of the bargain is modeled as the Nash bargaining solution:

$$
w_{u}=\underset{w_{u}}{\arg \max }\left\{U-U_{0}\right\}^{\lambda} \cdot\left\{\pi-\pi_{0}\right\}^{1-\lambda}, \quad \lambda \in[0,1],
$$

where $U$ is the union's objective function as given in (7) and $U_{0}$ is the union's disagreement point, $\pi$ and $\pi_{0}$ are the firm's profit and disagreement point, and $\lambda$ measures the union's relative bargaining power. ${ }^{19}$ The union's disagreement point in the bargain, $U_{0}$, is identified with the value of its objective function when the negotiation fails and all unskilled workers are unemployed,

$$
U_{0}=\ln \tilde{w}
$$

The firm's disagreement point is identified with the level of its profit when the negotiation on the wage for unskilled labor fails and only skilled workers are employed,

$$
\pi_{0}=\left(a_{s} \cdot l_{s}\right)^{\rho}-w_{s} \cdot l_{s}
$$

In this section, I additionally allow for the union and firms to take into full account the effects of the wage-setting on the level of benefits and the tax rate.

In this setting, the equilibrium wage for unskilled labor is given by:

$$
w_{u}=\frac{1}{2} \cdot e^{\frac{\lambda}{\lambda+\rho \cdot(1-\lambda)} \cdot\left(\phi \cdot \eta_{Y, l_{u}}+1-\rho\right)} \cdot \mu \cdot Y, \quad \text { with } \quad \eta_{Y, l_{u}}=\frac{\partial Y}{\partial l_{u}} \cdot \frac{l_{u}}{Y}
$$

where $\phi \in\{0,1\}$ is a dummy variable indicating whether or not the second round effects of the wage for unskilled labor on the level of benefits and the tax rate are accounted for in the wage bargain. The model in Sections 2 through 4 is nested in this specification (with $\lambda=1$ and $\phi=0)$. Qualitatively, the results of Propositions 1 through 3 remain valid in this setting. For details see Appendix A.3.

\subsection{CES Technology}

In Sections 2 through 4 the technology is separable in the two types of labor. This restriction is for simplicity. In this section, I consider a more general CES technology:

$$
Y=\left[\left(a_{u} \cdot l_{u}\right)^{\rho}+\left(a_{s} \cdot l_{s}\right)^{\rho}\right]^{\frac{\beta}{\rho}},
$$

where $\rho<1$ determines the elasticity of substitution $\sigma=1 /(1-\rho)$ and $\beta \in[0,1]$ is a returns-to-scale parameter. This specification nests the usual constant-returns-to-scale case $(\beta=1)$ and the specification from sections 2 through $4(\beta=\rho)$. In this setting, the equilibrium wage for unskilled labor is given by

$$
w_{u}=\frac{1}{2} \cdot e^{-\frac{1}{\eta_{l_{u}, w_{u}}}} \cdot \mu \cdot Y,
$$

\footnotetext{
${ }^{19}$ The Nash bargaining solution can be thought of as the limiting case of an alternating offer bargain where the parties take turns to make offers until one is accepted (see Binmore, Rubinstein, and Wolinski (1986)). The corresponding extensive-form game is described in Appendix A.2.
} 
where $\eta_{l_{u}, w_{u}}=\frac{\partial l_{u}}{\partial w_{u}} \cdot \frac{w_{u}}{l_{u}}$. In a competitive economy without labor market frictions, skillbiased factor augmenting technological change (as represented by an increase in $a_{s} / a_{u}$ ) leads to an increase (resp. decrease) in the relative wage for skilled labor $w_{s} / w_{u}$ if and only if the elasticity of substitution between unskilled and skilled labor is larger (resp. smaller) than $1 .{ }^{20}$ In the economy described in this paper, the relative wage is kept from fully adjusting to changes in relative productivity and skill-biased technological change has the respective employment effects: ${ }^{21}$

$$
\frac{\partial\left(1-l_{u}^{*}\right)}{\partial\left(a_{s} / a_{u}\right)} \gtreqless 0 \quad \sigma \gtreqless 1
$$

\subsection{Benefits as a Function of the Average Wage}

The central assumption of the model presented in Section 2, as expressed in (5), is that benefits or, more general, the reservation wage of unskilled workers depend on the average income. Since other workers' wages can be observed more easily than their total income, it might however be argued that the workers' reservation wage should be a function of the average wage level rather than the average income level. This reasoning takes into account the argument that workers compare their wages with the wages of the other workers as, eg, stated in the "fair wage-effort hypothesis" by Akerlof and Yellen (1990). They argue that what a worker considers her "fair wage" also depends on the wages of other - not necessarily equally qualified-workers. ${ }^{22}$ In the formal model, this means that equation (5) is replaced by $\tilde{w}=\mu \cdot(1-t) \cdot \frac{w_{u} \cdot l_{u}+w_{s}}{2}$. The results from Sections 3 and 4 are virtually unaffected. The existence of a unique equilibrium as well as the comparative static results from Propositions 1 through 3 remain valid.

\subsection{Is the Reservation Wage a Function of the Level of Benefits? Are the Benefits a Function of the Average Standard of Living?}

Two assumptions concerning the reservation wage's dependence on the average standard of living are made in Section 2. These are (i) that the reservation wage is equal to the level of benefits and (ii) that the level of benefits is a function of the average standard of living. One might consider either of them as quite strong assumptions. But as long as the wage for unskilled labor depends on some measure of a reservation wage/fall-back income that in turn is - among others - influenced by the average standard of living, the main conclusions remain valid. $\tilde{w}$ can be interpreted as any measure of the reservation wage that depends on some measure of the average standard of living.

\footnotetext{
${ }^{20}$ In equilibrium, the relative wage for skilled labor is given by $\frac{w_{s}}{w_{u}}=\frac{\partial Y / \partial l_{s}}{\partial Y / \partial l_{u}}=\left(\frac{a_{s}}{a_{u}}\right)^{\rho}$ in this setting. The sign of $\rho$ determines the sign of the effect of $a_{s} / a_{u}$ on $w_{s} / w_{u}$. See, eg, Acemoglu (2002) for a discussion of this issue.

${ }^{21}$ For details, see the Appendix A.4.

${ }^{22}$ See also footnote 11 .
} 
In fact, minimum wages are often indexed on the average wage. If - in addition - the minimum wage is binding, the same feedback effects are induced.

\subsection{Competitive Market for Unskilled Labor}

The previous sections relied on the assumption that the wage for unskilled labor is set by a labor union while the wage for skilled labor is flexible and clears the market. In some European countries, however, wages at the very bottom of the wage distribution are not covered by unions so that the market for unskilled labor is rather competitive. In this section, I argue that my results are robust with respect to these considerations.

Consider the following - very simple - modified version of the economy in Section 2. Assume the workforce consists of a continuum of mass one of heterogeneous workers indexed by $i \in[0,1]$.

The technology of the firm is $Y=\int_{0}^{1} a_{i} \cdot l_{i}^{\rho}$. $\mathrm{d} i$, where $l_{i}$ is employment of workers of skill type $i$.

Assume that wages for all skills be perfectly flexible so that labor markets at all skill levels clear. Assume further - as in Section 2-that each worker inelastically supplies one unit of labor whenever the prospective wage exceeds the level of welfare aid.

Equilibrium wages are given by $w_{i}=\frac{\partial Y}{\partial l_{i}}=\rho \cdot a_{i} \cdot{ }^{23}$

Assume that, in order to avoid poverty, the government pays welfare aid to those workers whose wage is too low to finance their living. These benefits are financed by an income tax. Following the considerations in the introduction, poverty is a relative concept and benefits depend on the average income level $\tilde{w}=\mu \cdot \bar{y}=\mu \cdot \int_{\iota}^{1} a_{i} \cdot \mathrm{d} i$, where $\iota$ is the marginal worker (or skill type) whose marginal productivity is exactly equal to the level of benefits.

For workers with types higher than $\iota$, working pays. Workers with types lower than $\iota$ prefer to receive social benefits. $\iota$ is the marginal worker who is indifferent between working and unemployment. $\iota$ is implicitly given by $w_{\iota}=a_{\iota} \cdot \rho \stackrel{!}{=} \tilde{w}=\mu \cdot \int_{\iota}^{1} a_{i} \cdot \mathrm{d} i$.

Assume for simplicity that $a_{i}$ be uniformly distributed over the interval $[\underline{a}, \bar{a}] .{ }^{24}$ The marginal worker is then determined by

$$
\iota=\frac{\rho \cdot\left(1-\frac{\bar{a}}{a}\right)-\mu+\sqrt{\rho^{2} \cdot\left(1-2 \cdot \frac{\bar{a}}{a}\right)+\left(\rho^{2}+\mu^{2}\right) \cdot\left(\frac{\bar{a}}{a}\right)^{2}}}{\mu \cdot\left(\frac{\bar{a}}{\underline{a}}-1\right)} .
$$

From the definition of $\iota$ follows that $\iota$ is equal to the rate of unemployment. ${ }^{25}$

\footnotetext{
${ }^{23}$ Again, the final good is chosen as numéraire.

${ }^{24}$ The productivity level of a type $i$ worker is then given by $a_{i}=\underline{a}+(\bar{a}-\underline{a}) \cdot i$.

${ }^{25}$ To be exact, the rate of unemployment is $u=\max \{0, \iota\}$. If $\iota$ is negative, even the least skilled worker prefers to work and there is no unemployment. The condition for unemployment in this setting is: $\iota>0$
} 
As in Section 4, I now analyze the effects of technical progress on the level of unemployment. Technical progress affects the productivities of the workers. The (uniform) distribution of skills is determined by the upper and lower bounds $\underline{a}$ and $\bar{a}$. A proportionate increase in both implies that the productivities of all workers increase at the same rate. A more than proportionate increase of the upper bound $\bar{a}$ relative to the lower bound $\underline{a}$ (ie an increase in $\bar{a} / \underline{a}$ ) implies that productivities of workers with higher skills increase faster than productivities of workers with lower skills (ie $a_{i} / a_{j}$ increases for any pair $i>j$ ).

It is straightforward to show that unemployment decreases with an increase in $\underline{a}$ (this is the equivalent to Proposition 1 and increases with an increase in $\bar{a}$. This is the analogue to Proposition 2.

More generally, unemployment increases if and only if $\bar{a} / \underline{a}$ increases. This finding corresponds directly to the result in Proposition 3.

Thus, as in Section 4, whenever technical progress is skill-biased, favoring the producitivities of the relatively more skilled, unemployment increases.

This example illustrates that the results obtained in Section 4 do not depend on the specification of the wage determination. In fact, even with perfectly competitive labor markets, (voluntary) unemployment can increase in the face of technical change. All that is required is that the worker's reservation wage (social benefits in this example) is linked to the average income level and that technical change is skill-biased. ${ }^{26}$

\section{Summary and Conclusion}

In this paper, I study the employment effects of skill-biased technological change when benefits are linked to per-capita income. This link to per-capita income introduces a tie between the wages for different skills.

\section{Standard Union Models}

In standard models of union wage setting, wages - especially at the lower end of the wage distribution - depend on the level of unemployment or social security benefits (which constitute the workers' reservation wage). As a consequence, these wages are downwardly rigid. This rigidity causes unemployment when productivity falls and wages do not adjust sufficiently.

\section{Indexing Benefits to Per Capita Income: The Wage for Unskilled Labor is Too Rigid And Overly Sensitive}

$\Leftrightarrow \quad \mu>\frac{2 \cdot \rho}{\frac{a}{a}+1}$. Unemployment occurs only if the replacement rate of unemployment benefits is sufficiently high relative to the productivity parameters.

${ }^{26}$ This example might be a better model for some European labor markets where wages at the lower end of the wage distribution are not covered by union wage bargaining but-contrary to anglo-saxon economies - the social security system is rather generous. 
The interdependence between wages and benefits yields an allocation where the wage for unskilled labor depends positively on the wage for skilled labor while the latter adjusts to clear the market for skilled labor. The obtained wage rigidity is a rigidity in the relation between the wages for unskilled and skilled labor. The wage for unskilled labor is too rigid with respect to the unskilled workers' productivity and it is overly sensitive to changes in the skilled workers' productivity.

\section{Skill-Biased Technical Change Leads to Increasing Unemployment}

If - as a result of skill-biased technological change - the productivity of the skilled workers rises faster than that of the unskilled workers, the wage of the latter increases by more than would be justified by their productivity gains (because it is linked to the skilled workers' wage via the benefits). As a result, employment of unskilled labor falls. The matter of concern here is not that the (unskilled workers') wage falls too little - as in standard union models - but that it rises too much.

\section{Accordance with Empirical Evidence}

The findings of this paper are consistent with the evolution of wages and employment of unskilled workers in Europe over the past decades. Wages for all skill levels have risen steadily over this period and, by and large, the employment prospects of the less skilled workers have deteriorated.

\section{"The European Unemployment Problem and the US Inequality Problem are Two Sides of the Same Coin" 27}

Technical change affects employment only if (i) it is "skill-biased" and (ii) the unskilled workers's wage is somehow linked to the skilled worker's wage. If one of these two conditions is not met, technical change only affects wages, leaving employment unchanged.

This result is consistent with the common view that it is the same factors that boost wage inequality in the U.S. and the UK and result in higher unemployment in (continental) Europe. In a model in which the welfare system is less generous and wages are to a greater extent market-determined - the alleged features of US labor markets - skill-biased technical change leads to an increase in wage inequality.

\section{Employment Effects of "Globalization"}

Increasing trade with low wage countries has been cited as a second "culprit" of the rise in wage inequality in the United States. In fact, in a two-sector version of this model, it can be shown that increasing trade with low wage countries (as modeled by a decrease in the relative price of the import good-whose production is assumed to be intensive in the use of unskilled labor) has exactly the same effect on wages and employment as skilled biased technical change. Increasing trade with low wage countries also leads to

\footnotetext{
${ }^{27}$ Krugman (1994).
} 
a (downward) shift in the relative demand for unskilled labor. As the relative wage for unskilled labor does not fully adjust, employment of unskilled labor falls.

\section{Policy Implications}

The findings in this paper have noteworthy policy implications. Any increase in the relative productivity (or more general in the relative "market value") of skilled workers leads to a higher rate of unemployment in this model - even if the absolute productivity of unskilled workers increases as well, but less than proportionately. Education policy should therefore aim at improving the skills of unskilled workers relative to those of the skilled.

\section{A Appendix:}

\section{A.1 Empirical Evidence}

\section{A.1.1 The Link Between Benefits and Per Capita Income}

The two central assumptions in this paper are, that (i) benefits are linked to per-capita income and (ii) benefits constitute the fall-back income for unskilled workers. While the latter assumption is quite common, the first deserves some more empirical support.

An implication of the link between benefits and per-capita income is that skill-biased technological change - or what ever else tends to boost wage dispersion (eg, increased competition from low wage economies) - should lift up the replacement ratios for unskilled workers. The replacement ratio for unskilled workers should thus be positively correlated with the skill-premium. In order to avoid problems with non-stationarity, I regressed first differences of the replacement ratio, $\Delta\left(\tilde{w}_{t} / w_{u, t}\right)=\tilde{w}_{t} / w_{u, t}-\tilde{w}_{t-1} / w_{u, t-1}$, on first differences of the skill-premium, $\Delta\left(w_{s, t} / w_{u, t}\right)=w_{s, t} / w_{u, t}-w_{s, t-1} / w_{u, t-1}$ for Germany, $1971-1995:^{28}$

$$
\widehat{\Delta \frac{\tilde{w}_{t}}{w_{u, t}}}=-\underset{(-1.30)}{0.009}+\underset{(4.76)}{0.441} \cdot \Delta \frac{w_{s, t}}{w_{u, t}} \quad\left(\text { adj. } R^{2}=0.4744\right)
$$

$t$-statistics are given in parentheses. The null hypothesis that changes in the skill-premium have no effect on changes in the replacement ratio is easily rejected at the 1 per cent significance level. This piece of evidence corroborates the assumption that the level of benefits depends not only on wages on the lower end of the wage distribution but also on high-skill wages.

\footnotetext{
${ }^{28} \tilde{w}$ is the Welfare Rate ("Sozialhilfe-Eckregelsatz") for a four-person household in Euros in consumer prices of 1990, Source: German Federal Ministry of Labor. $w_{u}$ is the wage for unskilled collar workers as categorized by the lowest performance group of blue collar workers ("Leistungsgruppe 3, Arbeiter"). $w_{s}$ is the wage for skilled workers as categorized by the highest performance group of white collar workers ("Leistungsgruppe 2, Angestellte"), Source: German Federal Statistical Office. On average over the period under consideration, both performance groups each account for roughly $10 \%$ of total employment.
} 


\section{A.1.2 Descriptive Evidence to Proposition 3}

Another implication of the model is that whatever tends to boost wage dispersion (be it skill-biased technological change or increased competition from low wage economies) leads to higher unemployment because the relative wage cannot fully adjust to changes in relative labor demand. The unemployment rate should thus be positively correlated with the skill-premium. A regression of the unemployment rate $u_{t}$ on the skill premium (both in first differences) for Germany, 1961 - 1995 yields:

$$
\widehat{\Delta u_{t}}=\underset{(2.09)}{0.002}+\underset{(3.73)}{0.045} \cdot \Delta \frac{w_{s, t}}{w_{u, t}} \quad\left(\text { adj. } R^{2}=0.2753\right)
$$

where $t$-statistics are given in parentheses. ${ }^{29}$ The effect of changes in the skill premium on the unemployment rate is highly significant. This substantiates the theoretical result in Proposition 3.

\section{A.2 The Extensive-Form Game Underlying the Nash Bargaining Solu- tion}

Consider the following game: The union and the firm bargain according to the alternatingoffers procedure. If the parties reach agreement on $w_{u}$ at time $t \cdot \Delta$, then the union's [respectively the firm's] payoff is

$$
U\left(w_{u}\right) \cdot e^{-\rho_{\text {union }} \cdot t \cdot \triangle}\left[\text { respectively } \pi\left(w_{u}\right) \cdot e^{-\rho_{\text {firm }} \cdot t \cdot \Delta}\right],
$$

where $U\left(w_{u}\right)$ and $\pi\left(w_{u}\right)$ are given by (7) and (2) respectively, $\triangle$ is the time span between two successive offers, and $\rho_{\text {union }}$ and $\rho_{\text {firm }}$ are the union's and the firm's discount rates. Immediately after any party rejects any offer at any time, with some probability, the negotiations break down in disagreement, and with the complementary probability, the game proceeds to time $(t+1) \cdot \triangle$ and the party makes its counteroffer. The union [respectively the firm] believes the probability of breakdown to be

$$
p_{\text {union }}=1-e^{-\theta_{\text {union }} \cdot \Delta}\left[\text { respectively } p_{\text {firm }}=1-e^{-\theta_{\text {firm }} \cdot \triangle}\right] .
$$

The payoffs in the case of breakdown at time $t \cdot \triangle$ are

$$
U_{0} \cdot e^{-\rho_{\text {union }} \cdot t \cdot \triangle} \text { and } \pi_{0} \cdot e^{-\rho_{\text {firm }} \cdot t \cdot \Delta} \text {, }
$$

where $U_{0}$ and $\pi_{0}$ are given by (16) and (17) respectively.

In the limit as the time between two offers shrinks to zero $(\triangle \rightarrow 0)$, the unique subgame perfect equilibrium to this game converges to the solution of the following maximization problem: ${ }^{30}$

$$
w_{u}=\underset{w_{u}}{\arg \max }\{U-\bar{U}\}^{\lambda} \cdot\{\pi-\bar{\pi}\}^{1-\lambda},
$$

\footnotetext{
${ }^{29}$ The data on unemployment rates are from the German Federal Labor Office.

${ }^{30}$ See Muthoo (1999).
} 
where $\lambda=\frac{\rho_{\text {firm }}+\theta_{\text {firm }}}{\rho_{\text {union }}+\rho_{\text {firm }}+\theta_{\text {union }}+\theta_{\text {firm }}}, \bar{U}=\frac{\theta_{\text {union }}}{\rho_{\text {union }}+\theta_{\text {union }}} \cdot U_{0}$, and $\bar{\pi}=\frac{\theta_{\text {firm }}}{\rho_{\text {firm }}+\theta_{\text {firm }}} \cdot \pi_{0}$.

If the parties' discount rates $\left(\rho_{\text {union }}\right.$ and $\left.\rho_{\text {firm }}\right)$ are sufficiently small relative to their beliefs of the breakdown probabilities $\left(\theta_{\text {union }}\right.$ and $\left.\theta_{\text {firm }}\right)$, this maximization problem is approximately equivalent to the one stated in (15).

\section{A.3 The Nash-Bargaining Solution}

Subsection 5.1 considers the case where the wage is determined in negotiations between the union and firms. The outcome of the negotiation is modeled as the general Nash Bargaining solution and is given by:

$$
w_{u}^{*}=e^{\frac{\lambda}{\lambda+\rho \cdot(1-\lambda)} \cdot\left(\frac{\phi \cdot \rho \cdot\left(\frac{\rho \cdot a_{u}}{w_{u}^{*}}\right)^{\frac{\rho}{1-\rho}}}{\left(\frac{\rho \cdot a_{u}}{w_{u}^{*}}\right)^{\frac{\rho}{1-\rho}}+a_{s}^{\rho}}+1-\rho\right)} \cdot \mu \cdot \frac{\left(\frac{\rho \cdot a_{u}}{w_{u}^{*}}\right)^{\frac{\rho}{1-\rho}}+a_{s}^{\rho}}{2}
$$

Comparative statics with respect to the productivity parameters yield:

$$
\begin{gathered}
\frac{\partial w_{u}}{\partial a_{u}} \cdot \frac{a_{u}}{w_{u}}=\frac{\eta_{Y, l_{u}} \cdot\left[\eta_{Y, l_{u}}+\left(1+\phi \cdot \rho \cdot \frac{\lambda}{\lambda+\rho \cdot(1-\lambda)}\right) \cdot \eta_{Y, l_{s}}\right]}{\rho \cdot(1-\rho)+\eta_{Y, l_{u}} \cdot\left[\eta_{Y, l_{u}}+\left(1+\phi \cdot \rho \cdot \frac{\lambda}{\lambda+\rho \cdot(1-\lambda)}\right) \cdot \eta_{Y, l_{s}}\right]}>0 \\
\frac{\partial l_{u}}{\partial a_{u}} \cdot \frac{a_{u}}{l_{u}}=\frac{\left(1-\frac{\lambda}{\lambda+\rho \cdot(1-\lambda)} \cdot \phi \cdot \eta_{Y, l_{u}}\right) \cdot \eta_{Y, l_{s}}}{1-\rho+\eta_{Y, l_{u}} \cdot\left(1+\frac{\lambda}{\lambda+\rho \cdot(1-\lambda)} \cdot \phi \cdot \eta_{Y, l_{s}}\right)}>0 \\
\frac{\partial w_{u}}{\partial a_{s}} \cdot \frac{a_{s}}{w_{u}}=\frac{\eta_{Y, l_{s}} \cdot\left(1-\frac{\lambda}{\lambda+\rho \cdot(1-\lambda)} \cdot \phi \cdot \eta_{Y, l_{s}}\right)}{1+\frac{\eta_{Y, l_{u}}}{1-\rho} \cdot\left(1+\frac{\lambda}{\lambda+\rho \cdot(1-\lambda)} \cdot \phi \cdot \eta_{Y, l_{s}}\right)}>0 \\
\frac{\partial l_{u}}{\partial a_{s}} \cdot \frac{a_{s}}{l_{u}}=\frac{\partial l_{u}}{\partial \frac{a_{s}}{a_{u}}} \cdot \frac{\frac{a_{s}}{a_{u}}}{l_{u}}=-\frac{\left(1-\frac{\lambda}{\lambda+\rho \cdot(1-\lambda)} \cdot \phi \cdot \eta_{Y, l_{u}}\right) \cdot \eta_{Y, l_{s}}}{1-\rho+\eta_{Y, l_{u}} \cdot\left(1+\frac{\lambda}{\lambda+\rho \cdot(1-\lambda)} \cdot \phi \cdot \eta_{Y, l_{s}}\right)}<0
\end{gathered}
$$

An increase in the unskilled workers productivity $a_{u}$ leads to an increase in both employment of and wages for unskilled labor. This result corresponds to Proposition 1.

An increase in the skilled workers productivity $a_{s}$ leads to an increase in the wage for unskilled labor and a decrease in unskilled employment. This result corresponds to Proposition 2.

Skill-biased technological change (an increase in $a_{s} / a_{u}$ ) leads to a decrease in employment. This result corresponds to Proposition 3. 


\section{A.4 CES Technology}

Subsection 5.2 considers the case where the firm's technology is of the more general CES type:

$$
Y=\left[\left(a_{u} \cdot l_{u}\right)^{\rho}+\left(a_{s} \cdot l_{s}\right)^{\rho}\right]^{\frac{\beta}{\rho}}
$$

In this setting, the equilibrium wage for and employment of unskilled labor are given by:

$$
w_{u}=\frac{1}{2} \cdot e^{-\frac{1}{\eta_{l_{u}, w_{u}}}} \cdot \mu \cdot Y \quad l_{u}=\frac{2}{\mu} \cdot \eta_{Y, l_{u}} \cdot e^{\frac{1}{\eta_{l_{u}, w_{u}}}}
$$

Employment effects of skill-biased technological change are given by:

$$
\frac{\partial l_{u}}{\partial a} \frac{a}{l_{u}}=-\rho \frac{\left(\frac{\frac{1}{1-\beta}-\frac{1}{1-\rho}}{\left(\frac{1}{1-\beta}+\frac{1}{1-\rho} \theta\right)^{2}}(1+\theta)+1\right) \frac{\theta}{1+\theta}}{1-\rho\left(\frac{\frac{1}{1-\beta}-\frac{1}{1-\rho}}{\left(\frac{1}{1-\beta}+\frac{1}{1-\rho} \theta\right)^{2}}(1+\theta)+1\right) \frac{\theta}{1+\theta}} \gtreqless 0 \quad \Leftrightarrow \quad \rho \lesseqgtr 0
$$

where $\theta=\left(\frac{a_{s}}{a_{u} l_{u}}\right)^{\rho}$. Skill-biased technological change has adverse employment effects if the elasticity of substitution between unskilled and skilled labor is larger than 1. If unskilled and skilled labor are complements $(\rho<0)$, employment increases in the presence of skillbiased technological change.

Proof. A sufficient condition for the above inequality to hold is that the numerator $\frac{\frac{1}{1-\beta}-\frac{1}{1-\rho}}{\left(\frac{1}{1-\beta}+\frac{1}{1-\rho} \theta\right)^{2}} \theta+\frac{\theta}{1+\theta}$ and the denominator $1-\rho\left(\frac{\frac{1}{1-\beta}-\frac{1}{1-\rho}}{\left(\frac{1}{1-\beta}+\frac{1}{1-\rho} \theta\right)^{2}} \theta+\frac{\theta}{1+\theta}\right)$ are both positive.

For $\rho \leq 0$, this is obvious. (Remember that $\beta \in(0,1)$.)

$\rho>0$ :

Sign of the numerator:

$$
\left(\frac{1}{1-\beta}-\frac{1}{1-\rho}\right) \frac{(1+\theta)}{\left(\frac{1}{1-\beta}+\frac{1}{1-\rho} \theta\right)^{2}}+1 \stackrel{?}{>} 0
$$

For $\beta>\rho$, the numerator is obviously positive.

For $\beta<\rho,\left(\frac{1}{1-\beta}-\frac{1}{1-\rho}\right) \frac{(1+\theta)}{\left(\frac{1}{1-\beta}+\frac{1}{1-\rho} \theta\right)^{2}}$ is most negative, when $\frac{(1+\theta)}{\left(\frac{1}{1-\beta}+\frac{1}{1-\rho} \theta\right)^{2}}$ is largest. Because $\frac{\partial \frac{(1+\theta)}{\left(\frac{1}{1-\beta}+\frac{1}{1-\rho} \theta\right)^{2}}}{\partial \theta}<0, \frac{(1+\theta)}{\left(\frac{1}{1-\beta}+\frac{1}{1-\rho} \theta\right)^{2}}$ is largest when $\theta$ is smallest, ie, $\theta=1$ :

$$
\left(\frac{1}{1-\beta}-\frac{1}{1-\rho}\right) \frac{(1+\theta)}{\left(\frac{1}{1-\beta}+\frac{1}{1-\rho} \theta\right)^{2}}+1=\frac{2\left(\frac{1}{1-\beta}-\frac{1}{1-\rho}\right)+\left(\frac{1}{1-\beta}+\frac{1}{1-\rho}\right)^{2}}{\left(\frac{1}{1-\beta}+\frac{1}{1-\rho}\right)^{2}}>0
$$




$$
\Leftrightarrow \quad \beta=\frac{2+\frac{1}{1-\rho}-\sqrt{1+4 \frac{1}{1-\rho}}}{1+\frac{1}{1-\rho}-\sqrt{1+4 \frac{1}{1-\rho}}}>1
$$

This means that the numerator can never be negative. Even with $\theta=1, \beta$ would have to be larger than 1 for $\left(\frac{1}{1-\beta}-\frac{1}{1-\rho}\right) \frac{(1+\theta)}{\left(\frac{1}{1-\beta}+\frac{1}{1-\rho} \theta\right)^{2}}+1$ to become negative.

This establishes that the numerator is positive. How about the denominator?

\section{Sign of the Denominator}

$$
1-\underbrace{\left(\frac{\frac{1}{1-\beta}-\frac{1}{1-\rho}}{\left(\frac{1}{1-\beta}+\frac{1}{1-\rho} \theta\right)^{2}} \theta+\frac{\theta}{1+\theta}\right)}_{>0} \stackrel{?}{>} 0
$$

The second part of the left hand side of the inequality is increasing with $\theta$ :

$$
\frac{\partial \rho\left(\frac{\frac{1}{1-\beta}-\frac{1}{1-\rho}}{\left(\frac{1}{1-\beta}+\frac{1}{1-\rho} \theta\right)^{2}} \theta+\frac{\theta}{1+\theta}\right)}{\partial \theta}>0 .
$$

Because the inequality holds even for $\theta \rightarrow \infty$ :

$$
\lim _{\theta \rightarrow \infty} 1-\rho\left(\frac{\frac{1}{1-\beta}-\frac{1}{1-\rho}}{\left(\frac{1}{1-\beta}+\frac{1}{1-\rho} \theta\right)^{2}} \theta+\frac{\theta}{1+\theta}\right)=1-\rho>0
$$

it must hold for all possible values of $\theta$. This establishes that the denominator is positive.

\section{References}

Acemoglu, D. (2002): "Technical Change, Inequality, and the Labor Market," Journal of Economic Literature, 40, 7-72.

Akerlof, G. A., And J. L. Yellen (1990): "The Fair Wage-Effort Hypothesis and Unemployment," Quarterly Journal of Economics, 105(2), 256-283.

Autor, D., L. Katz, and A. B. Krueger (1999): "Computing Inequality: Have Computers Changed the Labor Market?," Quarterly Journal of Economics, 113, 1169-1214.

Autor, D. H., and M. G. Duggan (2003): "The Rise in the Disability Rolls and the Decline in Unemployment," Quarterly Journal of Economics, 118(1), 157-205.

Binmore, K., A. Rubinstein, and A. Wolinski (1986): "The Nash-Bargaining Solution in Economic Modelling," Rand Journal of Economics, 17, 176-188. 
Blanchard, O., and L. F. Katz (1999): "Wage Dynamics: Reconciling Theory and Evidence," American Economic Review, 89(2), 69-74.

Büttner, T., and B. Fitzenberger (1998): "Central Wage Bargaining and Regional Wage Rigidity: Evidence from the Entire Wage Distribution," Discussion Paper 98-39, Centre for European Economic Research (ZEW).

DAvis, D. R. (1998): “Does European Unemployment Prop Up American Wages?," American Economic Review, 88(3), 478-494.

Foster, J. E. (1998): "Absolute versus Relative Poverty," American Economic Review, $88(2), 335-341$.

Freeman, R. (1995): "Are Your Wages Set in Beijing?," Journal of Economic Perspectives, $9(3), 15-23$.

Gottschalk, P., and T. M. Smeeding (1997): "Cross National Comparison of Earnings and Income Inequality," Journal of Economic Literature, 35(2), 633-678.

Krugman, P. (1994): "Past and Prospective Causes of High Unemployment," in: Federal Reserve Bank of Kansas City (Editor) (1994): "Reducing Unemployment: Current Issues and Policy Options, Proceedings of a Symposium in Jackson Hole", WY, Kansas City, MO.

(1995): "Growing World Trade: Causes and Consequences," Brookings Papers on Economic Activity I, pp. 327-362.

Levy, F., and R. J. Murnane (1992): "U.S. Earnings Levels and Earnings Inequality: A Review of Recent Trends and Proposed Explanations," Journal of Economic Literature, 30, 1333-1381.

Manning, A. (1993): "Wage Bargaining and the Phillips Curve: The Identification and Specification of Aggregate Wage Equations," The Economic Journal, 103(416), 98-118.

Muthoo, A. (1999): Bargaining Theory with Applications. Cambridge University Press, Cambridge.

Nickell, S. J., ANd B. Bell (1996): "Changes in the Distribution of Wages and Unemployment in OECD Countries," American Economic Review, 86(2), 302-307.

Saint-Paul, G. (1997): Dual Labor Markets: A Macroeconomic Perspective. MIT Press, Cambridge.

Siebert, H. (1997): "Labor Market Rigidities: At the Root of Unemployment in Europe," Journal of Economic Perspectives, 11(3), 37-54.

Veblen, T. (1899): The Theory of the Leisure Class. Allen and Unwin, London. 
Weiss, Y., and C. Fershtman (1998): "Social Status and Economic Performance: A Survey," European Economic Review, 42, 801-820.

Wood, A. (1994): North-South Trade, Employment, and Inequality: Changing Fortunes in a Skill Driven World. Clarendon Press, Oxford.

(1998): "Globalisation and the Rise in Labor Market Inequality," Economic Journal, 108(450), 1463-1482. 


\section{Discussion Paper Series}

Mannheim Research Institute for the Economics of Aging Universität Mannheim

To order copies, please direct your request to the author of the title in question.

\begin{tabular}{|c|c|c|c|}
\hline Nr. & Autoren & Titel & Jahr \\
\hline $30-03$ & $\begin{array}{l}\text { Axel Börsch-Supan, } \\
\text { Anette Reil-Held, } \\
\text { Christina B. Wilke }\end{array}$ & $\begin{array}{l}\text { Der Nachhaltigkeitsfaktor und andere } \\
\text { Formelmodifikationen zur langfristigen } \\
\text { Stabilisierung des Beitragssatzes zur GRV }\end{array}$ & 03 \\
\hline $31-03$ & $\begin{array}{l}\text { Barbara Berkel } \\
\text { Axel Börsch-Supan }\end{array}$ & $\begin{array}{l}\text { Renteneintrittsentscheidungen in Deutschland: } \\
\text { Langfristige Auswirkungen verschiedener } \\
\text { Reformoptionen }\end{array}$ & 03 \\
\hline $32-03$ & $\begin{array}{l}\text { Axel Börsch-Supan, } \\
\text { Hendrik Jürges, } \\
\text { OliverLipps }\end{array}$ & $\begin{array}{l}\text { SHARE: Building a Panel on Health, Aging and } \\
\text { Retirement in Europe }\end{array}$ & 03 \\
\hline $33-03$ & Florian Heiss & $\begin{array}{l}\text { Wie groß soll die Schwankungsreserve der } \\
\text { gesetzlichen Rentenversicherung sein? }\end{array}$ & 03 \\
\hline $34-03$ & $\begin{array}{l}\text { Axel Börsch-Supan, } \\
\text { Christina B. Wilke }\end{array}$ & $\begin{array}{l}\text { The German Public Pension System: } \\
\text { How it Was, How it Will Be }\end{array}$ & 03 \\
\hline $35-03$ & $\begin{array}{l}\text { Lothar Essig, } \\
\text { Anette Reil-Held }\end{array}$ & Chancen und Risiken der „Riester-Rente“ & 03 \\
\hline $36-03$ & $\begin{array}{l}\text { Barbara Berkel } \\
\text { Axel Börsch-Supan }\end{array}$ & $\begin{array}{l}\text { Pension Reform in Germany: } \\
\text { The Impact on Retirement Decisions }\end{array}$ & 03 \\
\hline $37-03$ & $\begin{array}{l}\text { Axel Börsch-Supan, } \\
\text { Anette Reil-Held and } \\
\text { Christina Benita } \\
\text { Wilke }\end{array}$ & $\begin{array}{l}\text { How to make a Defined Benefit System } \\
\text { Sustainable: } \\
\text { The "Sustainability Factor" in the German Benefit } \\
\text { Indexation Formula }\end{array}$ & 03 \\
\hline $38-03$ & Melanie Lührmann & $\begin{array}{l}\text { Demographic Change, Foresight and International } \\
\text { Capital Flows }\end{array}$ & 03 \\
\hline $39-03$ & $\begin{array}{l}\text { Joachim Winter and } \\
\text { Lothar Essig }\end{array}$ & $\begin{array}{l}\text { Item nonresponse to financial questions in } \\
\text { household surveys: An experimental study of } \\
\text { interviewer and mode effects }\end{array}$ & 03 \\
\hline $40-03$ & Christoph Buchheim & $\begin{array}{l}\text { Das Zusammenspiel von Wirtschaft, Bevölkerung } \\
\text { und Wohlstand aus historischer Sicht }\end{array}$ & 03 \\
\hline $41-03$ & Oliver Lipps & $\begin{array}{l}\text { Stochastische Bevölkerungsprognose für West- } \\
\text { und Ostdeutschland }\end{array}$ & 03 \\
\hline $42-03$ & Axel Börsch-Supan & $\begin{array}{l}\text { What are NDC Pension Systems? What Do They } \\
\text { Bring to Reform Satrategies? }\end{array}$ & 03 \\
\hline $43-04$ & Matthias Weiss & $\begin{array}{l}\text { Employment of Skill Biased Technological } \\
\text { Change when Benefits are Linked to Per-Capita } \\
\text { Income }\end{array}$ & 04 \\
\hline
\end{tabular}

